\title{
Sustainable utilization of oil palm fronds for cellulosic ethanol production: environmental life cycle assessment
}

\author{
C. Ofori-Boateng \& K. T. Lee \\ School of Chemical Engineering, Universiti Sains Malaysia, Malaysia
}

\begin{abstract}
The production of bioethanol involves the use of fossil fuels which are environmentally unfriendly when combusted to produce energy. In view of this, numerous debatable issues concerning the environmental sustainability of bioethanol production have emerged. Though the combustion of bioethanol itself contributes to reduction in greenhouse gas in the atmosphere, their production processes may offset their pros in terms of environmental safety. In this study, the environmental impact assessment of bioethanol production from oil palm fronds (OPFs) was evaluated using life cycle assessment (LCA) tool. Seven environmental impact categories were estimated with the help of $\mathrm{GaBi} 4$ software. It was found that climate change potential was the highest impact (5526.57 $\mathrm{g} \mathrm{CO}_{2}$ eq.) category for the bioethanol production system. However, the combustion of $100 \%$ bioethanol contributed a reduction of about $85.69 \%$ in greenhouse gas (GHG) emissions. The potential environmentally damaging unit operations were the oil palm cultivation and OPFs pretreatment units. Reduction in the use of toxic chemicals and fertilizers could help minimize the nitrous oxide and carbon dioxide emission which contributed to climate change impact. Keywords: life cycle assessment, bioethanol, oil palm fronds, lignocellulose, environmental sustainability, greenhouse gas emissions, global warming.
\end{abstract}

\section{Introduction}

With the aim of minimizing the dependency on fossil fuels in order to offset their environmental damages associated with their combustion, research and development on renewable energy resources have intensified. Liquid biofuels such as biodiesel and bioethanol have been better alternatives to fossil fuels in 
terms of environmental damages. However, among the types of biofuels, according to Hahn-Hagerdal et al. [1] bioethanol has emerged as the most produced, consumed and environmentally appealing in the world presently. In 2011 for instance, about 99.8 and 89.8 billion liters of bioethanol were produced and consumed in the world respectively according to the report by the energy information administration (EIA) [2]. Nonetheless, bioethanol presently are produced from edible crops often referred to as first generation feedstocks (e.g. corn, sugarcane etc.) whose utilization for fuel has become questionable due to their competition with food supply. Lignocellulosic biomass like oil palm fronds (OPFs) present better alternatives in this regard as these materials are considered waste and are available in large quantities all over the world OECD-FAO [3].

OPFs form the largest percentage of oil palm solid waste that is generated by the oil palm industry with annual generation capacity of 92.4 million tonnes (by dry weight) OECD-FAO [3]. In 2011, Malaysia as the second largest producer of palm oil generated about 54.24 million tonnes of OPFs (Wan Zahari et al. [4]). Due to the rich nutritive value of OPFs, after field management and harvesting, they are mostly left to rot in the plantation without any major commercial utilization (Yusoff [5]). However, for sustainable palm oil production, this waste could be transformed into many value added bio-products like cellulosic ethanol. OPFs are found to contain high holocellulose (cellulose and hemicellulose) content, which present them highly feasible feedstock for sugar and ethanol production. According to Ofori-Boateng and Lee [6], OPFs contain about 32\% cellulose, $22 \%$ hemicellulose, $12 \%$ lignin, $42 \%$ glucose and $18 \%$ xylose.

Though bioethanol combustion may be carbon neutral, their production processes make use of fossil fuels in large quantities which many overshadow the benefits biofuels bring. Life cycle assessment (LCA) is an effective tool used to evaluate the environmental performances of biofuel production systems by quantifying the emissions and waste generated in course of the process as well as helping with improvement suggestions. Quite a number of LCA studies have been carried out on cellulosic ethanol production and their use in vehicles by Lee and Ofori-Boateng [7], Spatari et al. [8] and Bai et al. [9] with the evolution of different results probably due to the absence of commercial cellulosic ethanol production plants. This study evaluates the environmental burdens associated with the production and use of bioethanol produced from OPFs via life cycle assessment which quantifies the environmental emissions during the production processes.

\section{Methodology}

LCA methodology used in this study followed the principles and framework of the International Organization for Standardization, ISO 14040 and 14044. The methodology consisted of four main stages namely:

1. Goal and scope definition

2. Life cycle inventory analysis (LCI)

3. Life cycle impact assessment (LCIA)

4. Results and interpretation. 


\subsection{Goal and scope definition}

\subsubsection{LCA goals}

The objectives of this study were to:

- Establish inventory of materials and energy resources associated with the production of bioethanol from oil palm fronds over its entire life cycle

- Establish a full chain energy analysis of the various unit operations involved in the bioethanol production

- Identify and compare the environmental damages associated with the unit operations within the bioethanol production system

- Identify the major unit operations which recorded high environmental loads and suggest possible improvement options

- Quantify the environmental burdens associated with the distribution and use of OPFs bioethanol in gasoline engines

The scope of the study includes the use of the 'well-to-wheel' LCA variant to assess the environmental impacts associated with the production and consumption of OPFs cellulosic ethanol.

\subsubsection{System boundary definition and functional unit}

Figure 1 shows the system boundary of the LCA study of OPFs cellulosic ethanol production. A functional unit of $1 \mathrm{~kg}$ bioethanol was considered for the LCA study. The system boundary includes oil palm cultivation, OPFs preparation, organosolv pretreatment of OPFs, simultaneous saccharification and fermentation (SSF), bioethanol purification, bioethanol distribution and combustion in gasoline engines. Though OPFs are considered waste that is generated during pruning and harvesting, they are always obtained during the oil palm cultivation process. In view of this, the cultivation of the oil palm for the generation of OPFs becomes necessary thus considered as part of the system boundary. During this stage, a lot of field establishments such as bush clearing, irrigation, prunning as well as the applications of fertilizers, pesticides and herbicides are carried out in order to attain maximal yield of oil palm fresh fruits.

Immediately after pruning and harvesting, the OPFs in their fresh states are transported to the ethanol refinery where they undergo preliminary preparations first before pretreatment. During the biomass preparation stage, the OPFs were shredded, washed, dried and milled into smaller particles. The milled OPFs then underwent organosolv pretreatment where ethanol and sodium hydroxide were used to to remove lignin and hemicelluloses in order to isolate the celluloses for bioethanol production.

The cellulose from OPFs were subjected to saccharification and fermentation in the same vessel using cellulase and baker's yeast (Saccharomyces cerevisiae) at $38^{0} \mathrm{C}$ for 72 hours. SSF is found to produce high ethanol yield compared to separate hydrolysis and fermenation (SHF) though LCA studies of cellulosic ethanol by SSF may give uncentainties due to lack of appropriate commercial technologies in the world presently (Spatari et al. [10]). 
Production and Transportation of pesticides, fertilizer, enzymes, yeast, ethanol, sodium hydroxide, electricity, diesel fuel, water, steam, machinery

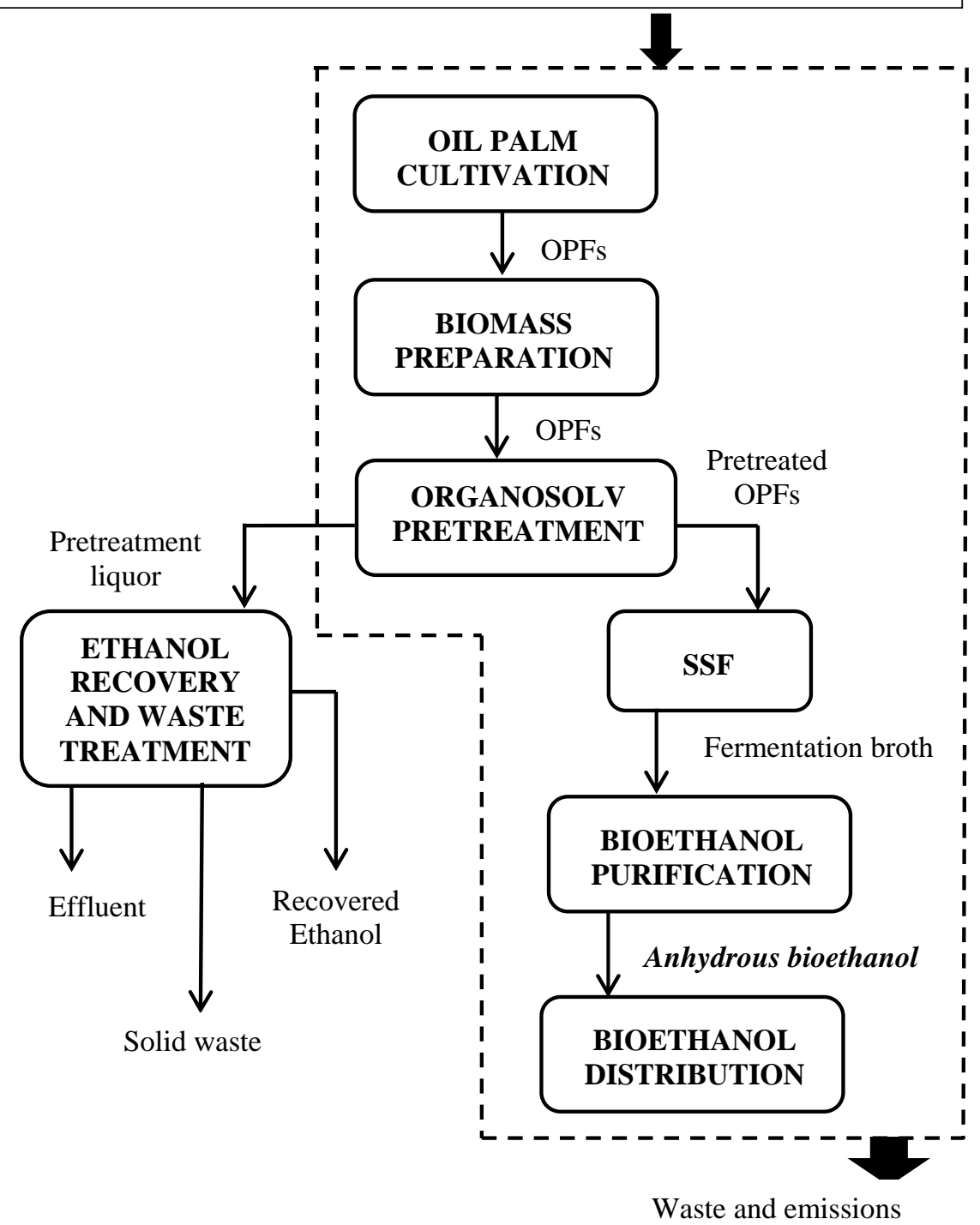

Figure 1: $\quad$ System boundary for LCA study of bioethanol production from OPFs.

During the SSF process, carbon dioxide is producedwhich is accounted for during the life cycle impact assessment stage for the SSF process. The fermentation broth from the SSF reactor was purified in a distillation unit in 
order to isolate the bioethanol from other components present in the broth. The treatment of wastewater from the refinery was excluded from the system boundary. Table 1 shows the process conditions for the major unit processes included in the system boundary. The bioethanol produced was then transported to a storage facility with the help of a diesel truck. Because it was assumed that the biorefinery was sited closer to a fuel station, the total distance for transporting to the storage facility was assumed to be $30 \mathrm{~km}$. The combustion of $100 \%$ bioethanol (E100) in a vehicle was assumed.

Table 1: $\quad$ Process conditions for the OPFs bioethanol production.

\begin{tabular}{|l|l|l|}
\hline Production stage & Process parameters & Value \\
\hline Organosolv & Ethanol & aq. $80 \% \mathrm{v} / \mathrm{v}$ \\
Pretreatment & NaOH & aq. $2 \% \mathrm{w} / \mathrm{v}$ \\
& Pretreatment temperature & $80^{0} \mathrm{C}$, \\
& Pretreatment yield & $55 \%$ \\
\hline SSF & Temperature & $38^{0} \mathrm{C}$ \\
& Time & $72 \mathrm{hr}$ \\
& Enzyme & Cellulase \\
& Yeast & S. cerevisiae \\
& pH & 5.0 \\
& SSF yield & $80 \%$ \\
\hline
\end{tabular}

\subsubsection{Assumptions and limitations of the study}

The LCA study was assumed for conditions of Malaysia where the production and use of OPFs were investigated over its life cycle. Though most of the data were taken from this location, other industrial or literature data were also used. It was assumed that $5.3 \mathrm{~kg}$ of palm seedlings were used to produce 13 tonnes of OPFs. The production of equipment, buildings, fertilizers, pesticides, diesel fuel, electricity, steam, water, and other chemicals like ethanol were not included in the system boundary. Oil palm cultivation was assumed to take place on previously logged-over forestland with progressively sustainable management practices associated with it. Harvesting and pruning in the plantation were assumed to be performed manually with the help of tractors. The LCA study used mass and energy allocation due to the production of more than one product.

\subsection{Life cycle inventory (LCI) analysis}

Table 2 shows the inventory for the LCA study. Data for the study were collected from different sources including literature values. Data used for the LCI analysis were obtained from Schmidt [11], Hong et al. [12], Jung et al. [13], Ecoinvent 99 database ( $\mathrm{GaBi} 4$ software), experimental results from OforiBoateng and Lee [6] and some estimations based on Malaysia's oil palm industry, Subranamiam et al. [14]. 
864 The Sustainable City VIII, Vol. 2

Table 2: $\quad$ Life cycle inventory of bioethanol production from OPFs.

\begin{tabular}{|c|c|c|c|}
\hline & Unit & Value & Total energy (MJ) \\
\hline \multicolumn{4}{|l|}{ OPFs cultivation } \\
\hline \multicolumn{4}{|l|}{ Input } \\
\hline Oil palm seeds & No. & 0.00391 & 0.1315 \\
\hline Water & $\mathrm{kg}$ & 4360.419 & 18.3138 \\
\hline Fertilizer & $\mathrm{kg}$ & 0.34613 & 7.7187 \\
\hline Pesticides & $\mathrm{kg}$ & 0.01494 & 0.7059 \\
\hline Diesel fuel & $\mathrm{kg}$ & 0.08375 & 4.0284 \\
\hline Human energy & MJ & 0.012678 & 0.0127 \\
\hline \multicolumn{4}{|l|}{ Output } \\
\hline OPFs & $\mathrm{kg}$ & 3.000 & 61.5300 \\
\hline Fresh fruit bunches & $\mathrm{kg}$ & 8.34 & 361.3722 \\
\hline \multicolumn{4}{|l|}{ Emissions to soil/water/air } \\
\hline Nitrogen $(\mathrm{N})$ & $\mathrm{kg}$ & 0.00966 & 0.4725 \\
\hline Phosphate & $\mathrm{kg}$ & 0.003865 & 0.06737 \\
\hline Pesticides & $\mathrm{kg}$ & 0.0016275 & 0.399665 \\
\hline Carbon dioxide $\left(\mathrm{CO}_{2}\right)$ & $\mathrm{kg}$ & 0.0264117 & 0.84834 \\
\hline $\mathrm{NO}_{\mathrm{x}}$ & $\mathrm{kg}$ & 0.000966 & 0.286027 \\
\hline $\mathrm{SO}_{2}$ & $\mathrm{~kg}$ & 0.000378 & 0.0111547 \\
\hline Carbon monoxide (CO) & $\mathrm{kg}$ & 0.049245 & 0.4979 \\
\hline \multicolumn{4}{|l|}{ Bioethanol production } \\
\hline \multicolumn{4}{|l|}{ Inputs } \\
\hline Ethanol & $\mathrm{kg}$ & 25.5 & 683.145 \\
\hline Sodium hydroxide & $\mathrm{kg}$ & 0.51 & 1.0013 \\
\hline Cellulase & $\mathrm{kg}$ & 0.2721 & 0.1104 \\
\hline Yeast & $\mathrm{kg}$ & 0.0341 & 0.3887 \\
\hline Water & $\mathrm{kg}$ & 127.5 & 0.5355 \\
\hline Electricity and steam & MJ & 7.50314 & 7.50314 \\
\hline Labour & MJ & 0.0408348 & 0.0408 \\
\hline \multicolumn{4}{|l|}{ Output } \\
\hline OPFs bioethanol & $\mathrm{kg}$ & 1.000 & 26.79 \\
\hline Wastewater & $\mathrm{kg}$ & 141.3348 & 2292.4508 \\
\hline \multicolumn{4}{|l|}{ Emissions to air/water/soil } \\
\hline $\mathrm{NOx}$ & $\mathrm{kg}$ & 0.00169 & 0.5013 \\
\hline $\mathrm{CO}_{2}$ & $\mathrm{~kg}$ & 0.747336 & 24.0044 \\
\hline $\mathrm{CO}$ & $\mathrm{kg}$ & 0.21546 & 2.1783 \\
\hline $\mathrm{SO}_{2}$ & $\mathrm{~kg}$ & 0.000658 & 0.0194 \\
\hline Methane (CH4) & $\mathrm{kg}$ & 0.00997 & 0.5234 \\
\hline Particulate matter & $\mathrm{kg}$ & 0.0008229 & 0.0008 \\
\hline Other emissions & $\mathrm{kg}$ & & \\
\hline
\end{tabular}




\section{Life cycle impact assessment and results}

\subsection{Energy analysis}

For the production of $1 \mathrm{~kg}$ bioethanol from OPFs, about 723.5 MJ of energy in the form of energy, chemicals and other inputs were consumed to produce about 449.69 MJ of useful outputs in the form of OPFs, bioethanol and fresh fruit bunches. The net energy ratio (NER) for the whole system was about 0.622 which is very low though closer to one. This low NER value shows that the amount of resources used to produce bioethanol from OPFs overweighs that which resulted as useful products. Again, the energy contents of the fertilizers especially were high thus low quality energy materials like organic fertilizers could help increase the NER value for the system. Fig. 2 summarizes the contributions of the various unit processes to the consumption of energy within the bioethanol production system.

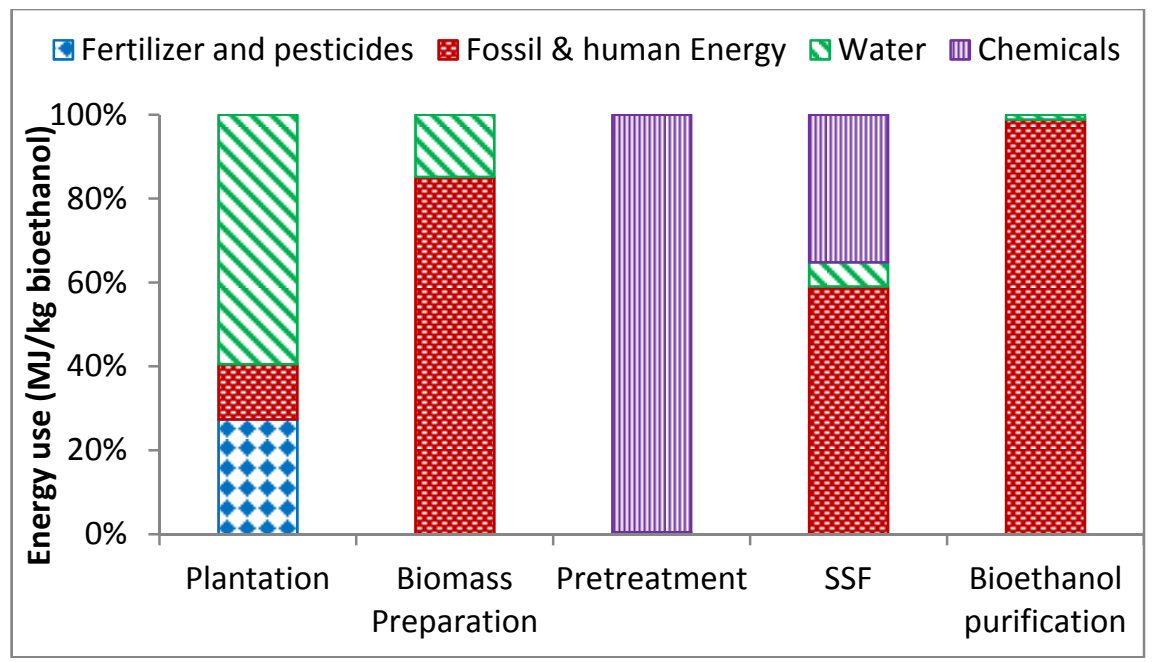

Figure 2: Energy use contributions by subunits within the bioethanol production system.

The pretreatment unit was found to consume about $95 \%$ of the total energy used throughout the life cycle of the bioethanol production with the bioethanol purification unit consuming the least amount of energy. The use of ethanol and sodium hydroxide were the major contributors to the high energy-use by the pretreatment unit. Of all the units, the plantation used the greatest amount of fossil fuel and human energy (4.041 MJ/kg) compared to the other units.

\subsection{Environmental impact assessment}

Seven environmental impact categories namely climate change (g $\mathrm{CO}_{2}$ eq.), ozone layer depletion (mg CFC-11 eq.), photochemical oxidation formation 
(g NMVOC), acidification (g $\mathrm{SO}_{2}$ eq.), eutrophication (g P eq.), ecotoxicity (g 1,4-DB eq.) and fossil fuel depletion (g oil eq.) were used to evaluate the environmental performances of the system. Fig. 3 shows the contributions of these impact categories by each process unit within the bioethanol production system. Fossil fuel depletion and climate change were the major environmental impact categories with great contributions in all the subunits.

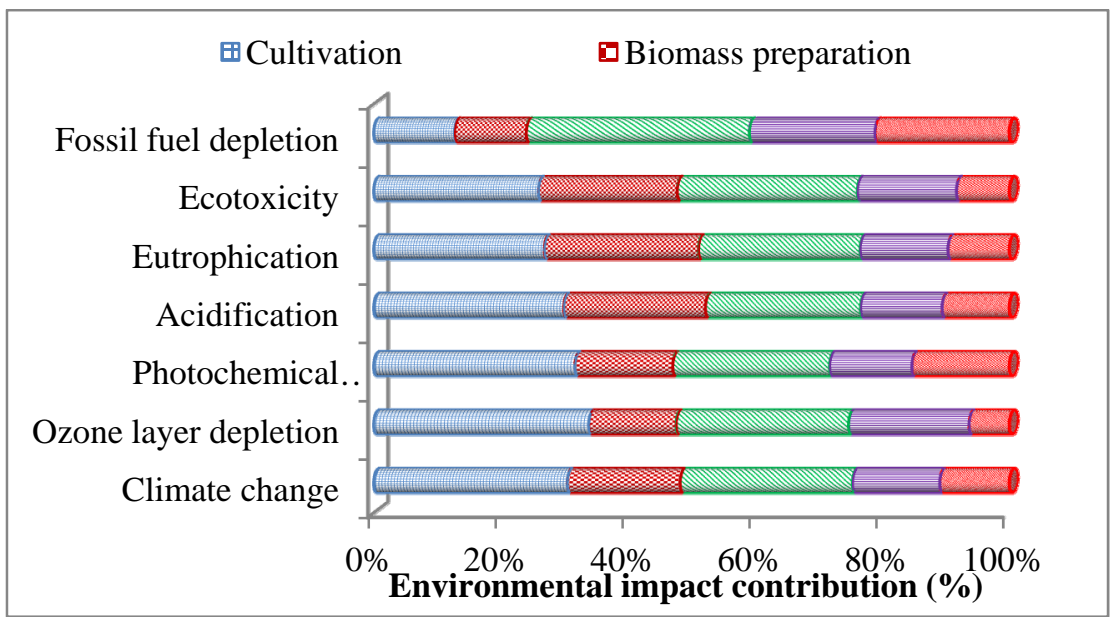

Figure 3: Environmental impact contributions by a system producing bioethanol from OPFs.

The plantation (1682.53 g $\mathrm{CO}_{2}$ eq.) and pretreatment (1498.72 g CO 2 eq.) units together contributed about $57.56 \%$ of the total environmental impacts from climate change potential. The use of fertilizers and pesticides during the cultivation of OPFs and the use of electricity and steam from fossil fuels during the pretreatment stages were the main reasons for the high climate change potential impacts to these units. Emissions such as $\mathrm{CO}_{2}$, $\mathrm{NOx}$, etc. were the major contributors to the impacts in the plantation and pretreatment units. The overall impact category contributions to the production of $1 \mathrm{~kg}$ OPFs bioethanol is shown in Table 3. Due to the use of fossil fuel, fertilizers and other chemicals

Table 3: $\quad$ Overall environmental impact of OPFs bioethanol production.

\begin{tabular}{|l|l|l|}
\hline Impact category & Unit & Value \\
\hline Climate change potential & g CO$_{2}$ eq. & 5526.57 \\
\hline Ozone layer depletion potential & mg CFC-11 eq. & 0.269 \\
\hline Photochemical oxidation potential & g NMVOC & 19.53 \\
\hline Acidification potential & g SO$_{2}$ eq. & 174.51 \\
\hline Eutrophication potential & g P eq. & 180.16 \\
\hline Ecotoxicity potential & g 1,4-DB eq. & 49.52 \\
\hline Fossil fuel depletion & g oil eq. & 822.30 \\
\hline
\end{tabular}


during the production processes, the overall climate change potential (5526.57 $\mathrm{g}$ $\left(\mathrm{CO}_{2}\right.$ eq.), fossil fuel depletion (822.30 g oil eq.), eutrophication and acidification potentials were very high. Fig. 4 shows the overall environmental impacts of the various subunits within the OPFs bioethanol production system.

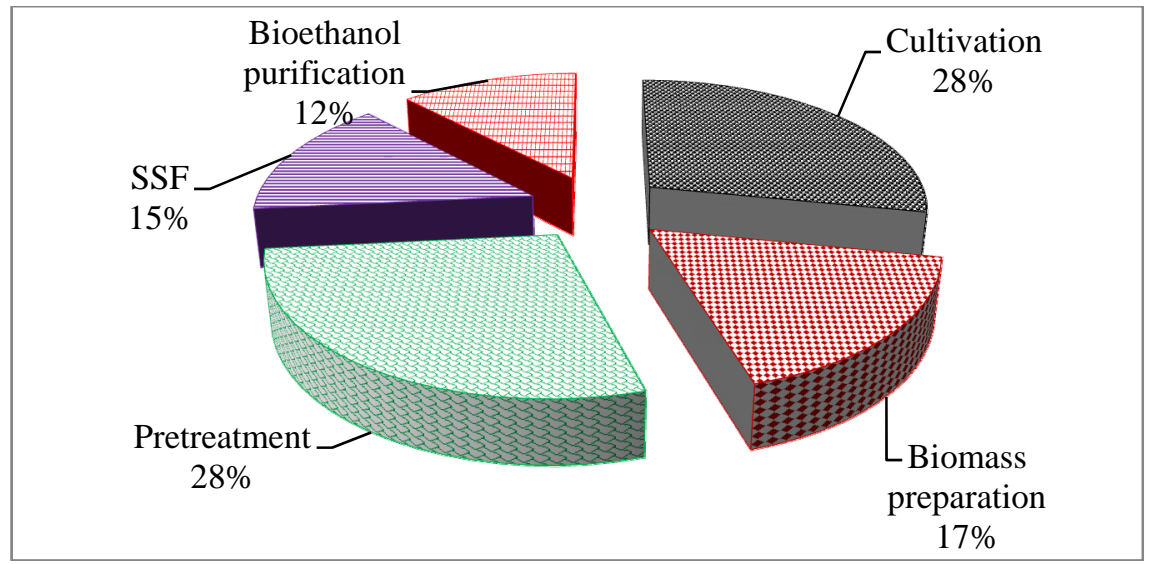

Figure 4: Overall environmental impacts of OPFs bioethanol production subunits.

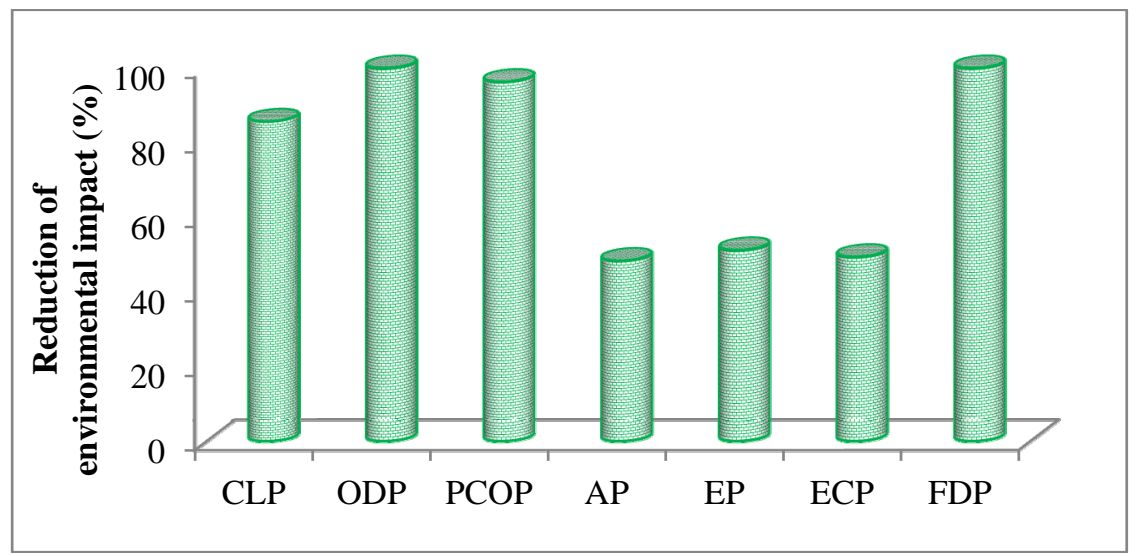

Figure 5: Environmental impact reduction for the combustion of $100 \%$ OPFs bioethanol (E100) (CLP-Climate change potential; ODP - Ozone layer depletion potential; PCOP - Photochemical oxidation potential; AP - Acidification potential; EP - Eutrophication potential; ECP - Ecotoxicity potential; FDP - Fossil fuel depletion potential).

The least impact came from the bioethanol purification unit (12\%) probably due to the limited or no use of chemicals during the purification process. Biomass preparation stage also utilized a lot of energy for drying, washing, 
grinding etc. which made it one of the environmentally damaging units within the system. Since the electricity and steam used in this study were assumed to be sourced from fossil fuel, the emissions such as $\mathrm{NO}_{\mathrm{x}}, \mathrm{CO}_{2}$ and particulate matter contributed to significant impact within the biomass preparation stage.

Comparing the emissions associated with the combustion of OPFs bioethanol (E100) and gasoline, it was found from the LCA study that E100 contributed a reduction of about $85.69 \%$ in greenhouse gas (GHG) emissions. E85 (i.e. 85\% bioethanol and $15 \%$ gasoline) from wheat straw have been found by Borrion et al. [15] to reduce GHG emissions by 73\%. Thus blends of bioethanol could also help reduce significant amount of GHGs upon combustion. Fig. 5 shows the reduction trends in the impact categories when E100 and gasoline are combusted. Notwithstanding the reduction in GHG savings from E100, the benefits it gives in terms of acidification, eutrophication and ecotoxicity potentials were low. Similar results on LCA of poplar bioethanol have been reported by Gonzalez-Garcia et al. [16] in which there were little decrease in acidification, eutrophication and ecotoxicity potentials.

\section{Conclusions}

Environmental impact assessment of bioethanol production from oil palm fronds (OPFs) was performed using life cycle assessment (LCA) tool. The energy analysis indicated a net energy ratio (NER) of 0.622 which was very low due to the use of raw materials whose energy contents outweighed those of the useful products. The LCA results showed that about $5526.57 \mathrm{~g} \mathrm{CO}_{2}$ eq. was released into the environment during the production of OPFs bioethanol starting from OPFs production to bioethanol recovery. Due to the use of toxic chemicals and fertilizers, the cultivation and pretreatment units recorded the highest environmental impacts resulting from the emission of nitrous oxide and carbon dioxide from the use of the chemicals. However, the combustion of OPFs bioethanol itself (i.e. E100) could help reduce greenhouse gas emission by $85.69 \%$. According to this study, though the production of OPFs bioethanol was environmentally polluting, the use of the fuel itself saved the environment from dangerous greenhouse gas emissions.

\section{References}

[1] Hahn-Hagerdal, B., Galbe, M., Gorwa-Grauslund, M.F., Liden, G. and Zacchi, G., Bioethanol-the fuel of tomorrow from the residues of today. Trends in Biotechnology, 24(12), pp. 549-556, 2006.

[2] EIA (Energy Information Agency of the United States), International energy statistics. Biofuels production. 2011. Available at http://www.eia. gov/cfapps/ipdbproject. Assessed March, 2012.

[3] OECD-FAO (Organization for Economic Cooperation and DevelopmentFood and Agriculture Organization), OECD-FAO Agricultural Outlook 2011-2020, 2011. Available at http://www.oecd.org/site/oecdfaoagriculturaloutlook/48186214.pdf, accessed on March, 2012. 
[4] Wan Zahari, M., Sato, J., Furuichi, S., Sukri, I.M., Bakar, C.A. and Yunus, I., Recent development on the processing and utilisation of complete feed based on oil palm fronds (OPF) for ruminant feeding in Malaysia. Lignocellulose: materials for the future from the tropics, ed. R. Tanaka, L.H. Cheng, JIRCAS Working Report, Proceedings of 3rd USM-JIRCAS Joint International Symposium, Penang, Malaysia, pp. 125-129, 2004.

[5] Yusoff, S., Renewable energy from palm oil - innovation on effective utilization of waste, Journal of Cleaner Production, 14(1), pp. 87-93, 2006.

[6] Ofori-Boateng, C. and Lee, K.T., Sono-assisted organosolv/ $\mathrm{H}_{2} \mathrm{O}_{2}$ pretreatment of oil palm (Elaeis guineensis Jacq.) fronds for recovery of fermentable sugars: Optimization and severity evaluation, Fuel, 115(1-4), pp. 170-178, 2013.

[7] Lee, K.T. and Ofori-Boateng, C., Sustainability of biofuel production from oil palm biomass, Springer Singapore, pp. 149-187, 2013.

[8] Spatari, S., Zhang, Y. and Maclean, H., Life cycle assessment of switch grass and corn stover-derived ethanol-fueled automobiles. Environmental Science and Technology, 39(24), pp. 9750-9758, 2005.

[9] Bai, Y., Luo, L. and van der Voet, E., Life cycle assessment of switchgrassderived ethanol as transport fuel. International Journal of Life Cycle Assessment, 15(5), pp. 468-477, 2010.

[10] Spatari, S., Bagley, D.M. and MacLean, H.L., Life cycle evaluation of emerging lignocellulosic ethanol conversion technologies. Bioresource Technology, 101 (2), pp. 654-667, 2010.

[11] Schmidt, J.H., Life assessment of rapeseed oil and palm oil. Ph.D. Thesis, Part 3: Lifecycle inventory of rapeseed oil and palm oil. Department of Development and Planning, Aalborg University, Aalborg, 2007.

[12] Hong, L.S., Ibrahim, D. and Omar, I.C., Oil palm frond for the production of bioethanol. International Journal of Biochemistry and Biotechnology, 1(1), pp. 7-11, 2012.

[13] Jung, Y.H., Kim, S., Yang, T.H., Lee, H.J., Seung, D., Park, Y.C., Seo, J.H., Choi, I.G. and Kim, K.H. Aqueous ammonia pretreatment, saccharification, and fermentation evaluation of oil palm fronds for ethanol production. Bioprocess and Biosystems Engineering, 35(9), pp. 1497-1503, 2012.

[14] Subranamiam, V., Chow, M.C. and Ma, A.N., Energy Database of the Oil Palm. Palm Oil Engineering Bulletin, EB70 (94), pp. 29-42, 2004.

[15] Borrion, A.L., McManus, M.C. and Hammond, G.P., Environmental life cycle assessment of bioethanol production from wheat straw. Biomass and Bioenergy, 47(1), pp. 9-19, 2012.

[16] Gonzalez-Garcia, S., Gasol, C.M., Gabarrell, X., Rieradevall, J., Moreira, M.T. and Feijoo, G., Environmental profile of ethanol from poplar biomass as transport fuel in Southern Europe. Renewable Energy, 35(1), pp. 10141023, 2010. 